\title{
Utility of PET-CT in non-small cell lung cancer clinical stage IB-IIA according to AJCC 8th edition staging system: an alternative to invasive mediastinal staging?
}

\author{
Agustin Buero $^{1}$ (iD, Domingo J Chimondeguy ${ }^{1,2}$, Rodolfo Auvieux ${ }^{1}$, Gustavo A Lyons ${ }^{1}$, Leonardo G Pankl ${ }^{1}$, Guillermo Puchulo² and \\ Silvia Quadrelli3
}

${ }^{1}$ Department of Thoracic Surgery, Buenos Aires British Hospital, Perdriel 74, C1280AEB, Buenos Aires, Argentina ${ }^{2}$ Department of Thoracic Surgery, Austral University Hospital, Av Juan Domingo Perón 1500, B1629AHJ, Buenos Aires, Argentina ${ }^{3}$ Department of Pneumonology, Buenos Aires British Hospital, Perdriel 74, C1280AEB, Buenos Aires, Argentina ahttps://orcid.org/0000-0001-5984-3270

\section{Abstract}

Objective: Mediastinal nodal staging in lung cancer is essential to determine treatment strategy and prognosis. There are controversies as to whether a mediastinal negative result in PET-CT may spare the invasive staging of the mediastinum. The main endpoint is to evaluate the negative predictive value (NPV) of PET-CT in non-small cell lung cancer (NSCLC) clinical stage IB-IIA without clinical nodal involvement. The secondary endpoint is to evaluate the prevalence of mediastinal and hilar nodal affection in this population.

Methods: We performed an observational descriptive study from January 2010 to January 2020, including 76 patients with clinical stage IB-IIA, who underwent pulmonary resection with systematic nodal sampling (pre-determined lymph node stations based on tumour location) for primary NSCLC. Clinically, nodal involvement was defined as any lymph node greater than $1 \mathrm{~cm}$ in the short axis on a CT or with metabolic uptake greater than 2.5 SUV on PET-CT. The prevalence of nodal metastases was recorded.

Results: Fifty six patients had clinical stage IB and 20 had clinical stage IIA. Mean tumour size was $3.74 \pm 0.5 \mathrm{~cm}$. Lobectomy was the resection procedure most frequently performed. Of the 76 patients with clinical NO by PET-CT who underwent surgical resection, 10 (13.1\%) were upstaged to $\mathrm{pN} 1$ and none were upstaged to pN2. NPV of PET-CT for overall nodal metastasis was $87 \%$ (95\% Cl: 0.79-0.94). NPV of PET-CT for N2 metastasis was $100 \%$.

Conclusion: PET-CT might be an alternative to invasive mediastinal staging in patients with NSCLC clinical stage IB-IIA who are surgical candidates. Further prospective multiinstitutional studies are necessary to verify the external validity of our study.

Keywords: lung cancer, staging, PET-CT, mediastinoscopy, occult N2 disease
Correspondence to: Agustin Buero

Email: a_buero@hotmail.com

ecancer 2021, 15:1250

https://doi.org/10.3332/ecancer.2021.1250

Published: $15 / 06 / 2021$

Received: 07/01/2021

Publication costs for this article were supported by ecancer (UK Charity number 1176307).

Copyright: () the authors; licensee ecancermedicalscience. This is an Open Access article distributed under the terms of the Creative Commons Attribution License (http:// creativecommons.org/licenses/by/3.0), which permits unrestricted use, distribution, and reproduction in any medium, provided the original work is properly cited. 


\section{Introduction}

The accuracy of clinical mediastinal lymph node staging has an implication in the treatment strategy. It is the most relevant factor to determine resectability as the presence of metastasis at this lymph node stations implies an advanced stage (stage IIIA or IIIB). Invasive staging in all patients is controversial. Nowadays is mostly performed in selected patients when there is a high suspicion of lymph node metastasis. According to non-small cell lung cancer (NSCLC) international guidelines [1-4], the criteria include: suspected mediastinal and/or hilar lymphatic involvement in CT (over $1 \mathrm{~cm}$ in short axis), hilar and/or mediastinal lymph nodes uptake in PET-CT (SUV over 2.5), central tumours (up to fourth bronchial generation), multiple lung tumours and those greater than $3 \mathrm{~cm}$. In line with international guidelines, PET-CT does not play a decisive role in clinical stages IB-IIA in terms of mediastinal staging, since these patients have a risk factor (tumour size) for N2 and the mediastinum should be explored invasively anyway [1, 5-9]. Although mediastinal staging using PET-CT is superior to CT, many studies show that this method is not flawless. A positive result must be confirmed by histological study due to its low positive predicted value (PPV) [1, 5-8]. Nevertheless, there are controversies whether a negative mediastinal result in PET-CT could spare invasive staging [10-12]. Most authors consider that invasive staging should be performed in patients with risk factors for occult N2 despite a negative result in PET-CT. Hence, according to several international guidelines, invasive staging can only be spared in clinical T1 NO MO patients as their reported prevalence of $\mathrm{N} 2$ is below $10 \%$. However, in our practice, we have seen that patients who underwent surgery for tumours between 3 and $5 \mathrm{~cm}$ without clinical nodal involvement did not have mediastinal nodal metastasis in samples obtained neither by mediastinoscopy nor in surgical specimens. We hypothesise that the absence of clinical node involvement in PET-CT could be an alternative to invasive mediastinal staging in clinical stage IB-IIA. The aim of this study is to evaluate the negative predictive value (NPV) of PET-CT in patients with NSCLC tumours $>3 \mathrm{~cm}$ and $\leq 5 \mathrm{~cm}$ without clinical nodal involvement and to describe the prevalence of mediastinal (N2) and hilar (N1) metastasis in the study population.

\section{Methods}

This is a descriptive observational study performed from January 2010 to January 2020, where 76 patients were included. Data were collected prospectively and retrospectively from database of two large University Hospitals (Buenos Aires British Hospital and Austral University Hospital). The Institutional Review Committee of the British Hospital of Buenos Aires reviewed and approved this study (CRIHB number: \# 802).

\section{Inclusion criteria}

Patients with clinical tumours over $3 \mathrm{~cm}$ and less than or equal to $5 \mathrm{~cm}$ in diameter without clinical nodal involvement (hilar and mediastinal), who underwent pulmonary resection with systematic nodal sampling for primary lung cancer, were included. These correspond to clinical stages IB and IIA, according to the American Joint Committee on Cancer (AJCC) 8th edition Cancer Staging Manual. Preoperative staging was performed according to the 8th edition of the International Association for the Study of Lung Cancer. All CT scans were done in one of the two hospitals mentioned, with $5 \mathrm{~mm}$ thick sections throughout the entire lung during inspiration in the supine position during the injection of intravenous iodinated contrast agent. Data on tumour location, size and standardized uptake value (SUV) were recorded from chest CT and positron emission tomography-computed tomography (PET-CT). Measurements of tumours were performed according to The Fleischner Society: transverse (axial) sections in lung window, unless the maximal dimension lies in a coronal or sagittal plane [13]. Peripheral tumours were defined as those that were located beyond the fourth generation bronchiole, which usually corresponds to the outer two thirds of the lung field (measured as the radial distance from the hilum to the lung periphery). PET-CT scans had been performed to all patients using multidetector CT integrated high-resolution PET-CT scanners after an intravenous injection of Fluorodeoxyglucose F 18 (18F-FDG) (studies from outside institutions were accepted). Clinically, nodal involvement was defined as any lymph node greater than $1 \mathrm{~cm}$ in the short axis on a CT or with metabolic uptake greater than 2.5 SUV on PET-CT. Brain magnetic resonance imaging was performed only if the patient had neurological symptoms. Patients must have been suitable for lung surgery: optimal pulmonary function tests, Eastern Cooperative Oncology Group performance status score 0 and 1 and no cardiological contraindication. Non-invasive mediastinal staging (CT and PET-CT) was mandatory 
within the previous month to lung resective surgery. Having a preoperative invasive mediastinal evaluation was not required as inclusion criteria in the study. When done, it was through cervical mediastinoscopy. Systematic nodal sampling was defined as the biopsy of lymph nodes from pre-determined lymph node stations based on tumour location. Postoperative proven NSCLC histology was required and those with different histology were excluded. Final pathologic staging was classified according to the AJCC 8th edition Cancer Staging Manual. Patients with primary NSCLC (cT2a/b) with clinical nodal involvement, previous lung cancer, preoperative chemotherapy-radiotherapy for lung cancer (neoadjuvant treatment) or with PET-CT contraindications were excluded.

\section{Pulmonary resection and mediastinoscopy}

In all patients who underwent a pulmonary resection, systematic nodal sampling with at least four stations was included. A systematic node sample was performed according to tumor location (2R, 4R, 7 and 10R for right-sided tumor's; 5, 6, 7 and 10L for left-sided tumor's). Paraoesophageal and pulmonary ligament nodal groups were not explored in all lower lobectomies since it depended on the decision of each surgeon during the surgery. Lobar, segmental and sub-segmental nodal groups were sent together with lung specimen. Taking into account that thoracotomy or left video-assisted thoracoscopic surgery (VATS) cannot satisfactorily explore $2 \mathrm{~L}$ and $4 \mathrm{~L}$ nodes (suboptimal intraoperative staging) and that most left-sided tumours did not have mediastinal invasive staging, we decided to analyse whether there were mediastinal recurrences in the follow-up of these patients.

For patients who underwent cervical mediastinoscopy previous to pulmonary resection, our intention was to analyse the following stations: $2 R, 4 R, 7,4 L$ and $2 \mathrm{~L}$. At least three nodal stations, including stations 4R, 4L and 7, were biopsied.

\section{Analysis}

Statistical analysis was performed using SPSS 13.0 statistical software. The diagnostic value of PET scanning was compared to surgical lymph node assessment by calculating NPV. NPV was calculated as (true negative)/(true negative + false negative). All data are presented as mean +/- standard deviation or counts with percentages.

\section{Results}

Between 2010 and 2020, 76 patients that matched inclusion criteria were selected for the study. There were 42 male and 34 female patients, with a mean age of $67 \pm 8.9$ years. Fifty six patients belonged to a clinical stage IB and 20 to clinical stage IIA. Mean tumour size was $3.74 \pm$ $0.5 \mathrm{~cm}$ (range: 1.96). All patients underwent pulmonary resection with systematic nodal sampling. Lobectomy was the resection procedure most frequently performed (94.7\%). The mean lymph node and mean nodal stations evaluated per patient was $10.1 \pm 4.7$ and $4.3 \pm 0.9$, respectively (Table 1). Lobar, segmental and sub-segmental nodal groups were not included in the systematic nodal sampling, since they were sent together with lung specimen. Seventeen patients $(23.7 \%)$ were staged by mediastinoscopy prior to surgery. None of them had mediastinal lymph node affection neither in mediastinoscopy nor in systematic nodal sampling during resective surgery.

Mean follow-up of left-sided tumours was $25.4 \pm 15.1$ months (median: 24.4 months). Of the 19 patients with left-sided tumours, 3 patients underwent preoperative mediastinoscopy. In the follow-up, one patient developed mediastinal recurrence 8 months after the resective surgery and passed away 10 months after recurrence diagnosis due to COVID-19 pneumonia (19-month total survival). Of the remaining 16 patients who did not undergo mediastinoscopy, none of them had mediastinal recurrence and 3 patients had systemic recurrence (bone, adrenal and contralateral lung) with a mean time of manifestation of $15 \pm 9.4$ months.

Of the 76 patients with clinical stage NO by PET-CT who underwent surgical resection, 10 (13.1\%) were upstaged to pN1 and none were upstaged to pN2. Multilevel pN1 was detected in one patient (groups 10 and 11). Details of nodal evaluation and upstaging during pulmonary resection are shown in Table 2. NPV of PET-CT for overall nodal metastasis was $87 \%$ (95\% Cl: 0.79-0.94). NPV of PET-CT for N1 was the same as overall nodal metastasis. NPV of PET-CT for N2 metastasis was $100 \%$. 
Table 1. Clinical characteristics

\begin{tabular}{|c|c|c|}
\hline \multicolumn{3}{|c|}{ Clinical characteristics } \\
\hline & Variable & $\begin{array}{c}\text { Mean } \pm \text { standard derivation or counts with } \\
\text { percentages }\end{array}$ \\
\hline \multicolumn{3}{|l|}{ Gender } \\
\hline & Male & $43(56.5 \%)$ \\
\hline & Female & 33 (43.5\%) \\
\hline Age (y) & & $67 \pm 8.9$ \\
\hline \multicolumn{3}{|l|}{ Clinical Stage } \\
\hline & IB (T2a NO MO) & $56(73.7 \%)$ \\
\hline & IB (T2b NO MO) & $20(26.3 \%)$ \\
\hline cT size $(\mathrm{cm})$ & & $3.74 \pm 0.5$ \\
\hline \multicolumn{3}{|l|}{ Location } \\
\hline & Central & $13(17.1 \%)$ \\
\hline & Peripheral & $63(82.9 \%)$ \\
\hline \multicolumn{3}{|l|}{ Side } \\
\hline & Right & $57(75 \%)$ \\
\hline & Left & 19 (25\%) \\
\hline SUV max & & $8.2 \pm 5$ \\
\hline \multicolumn{3}{|c|}{ Type of surgery } \\
\hline & Pneumonectomy & $2(2.7 \%)$ \\
\hline & Bilobectomy & $1(1.3 \%)$ \\
\hline & Lobectomy & $72(94.7 \%)$ \\
\hline & ULL & 54 \\
\hline & LLL & 18 \\
\hline & Segmentectomy & $1(1.3 \%)$ \\
\hline No. of LND & & $4.3 \pm 0.9$ \\
\hline No. of LN & & $10.1 \pm 4.7$ \\
\hline \multicolumn{3}{|l|}{ Histology } \\
\hline & Adenocarcinoma & $69(90.8 \%)$ \\
\hline & Squamous cell & $7(9.2 \%)$ \\
\hline
\end{tabular}

ULL: upper lobe lobectomy; LLL: lower lobe lobectomy; LNS: lymph node stations; LN: lymph node

\section{Discussion}

An accurate nodal staging in lung cancer is essential to define treatment strategy and prognosis. International guidelines recommend performing an invasive mediastinal staging in clinical stages IB-IIA due to a high rate of occult N2 (>10\%) and a low NPV of PET-CT (<90\%) [1-4]. Studies that back up international guidelines were performed using the 7th edition of Classification of Malignant Tumors (TNM) T: tumor; N: nodal; M: metastasis for NSCLC, which has two important differences with the current edition. The first one is that in the previous edition, clinical stages IB-IIA included patients with N1 tumours, whilst the 8th edition does not (Table 3). The second one is that T2 factor 
differs: in the 7th edition, tumours between 3 and $7 \mathrm{~cm}$ were included, while the 8th edition includes tumours between 3 and $5 \mathrm{~cm}$ (Table 4). Nowadays, tumours over $5 \mathrm{~cm}$ and $\mathrm{cN} 1$ are included in stage IIB requiring mediastinal invasive staging due to high incidence of occult N2.

Table 2. Lymph node evaluation and upstaging during pulmonary resection

\begin{tabular}{|c|c|c|}
\hline Lymph node stations & $\begin{array}{c}\text { No. of patients with nodal stations } \\
\text { sampled } \\
(\mathbf{n}=76)\end{array}$ & $\begin{array}{c}\text { No. of patients with } \\
\text { nodal metastasis } \\
(\mathbf{n}=10)\end{array}$ \\
\hline $2 \mathrm{R}$ & 30 & 0 \\
\hline $2 \mathrm{~L}$ & 0 & 0 \\
\hline $4 \mathrm{R}$ & 53 & 0 \\
\hline $4 \mathrm{~L}$ & 0 & 0 \\
\hline 5 & 18 & 0 \\
\hline 6 & 15 & 0 \\
\hline 7 & 67 & 0 \\
\hline 8 & 6 & 0 \\
\hline 9 & 9 & 3 \\
\hline $10 \mathrm{R}$ & 51 & 1 \\
\hline $10 \mathrm{~L}$ & 12 & 7 \\
\hline Bronchopulmonary & 67 & \\
\hline
\end{tabular}

Table 3. Differences between stages IB-IIA in $6^{\text {th }}, 7^{\text {th }}$ and $8^{\text {th }}$ edition of TNM classification

\begin{tabular}{|c|c|c|c|}
\hline \multicolumn{4}{|c|}{ TNM } \\
\hline Stage & $6^{\text {th }}$ ed. & $7^{\text {th }}$ ed. & $8^{\text {th }}$ ed. \\
\hline IB & T2 NO MO & T2a NO MO & T2a NO MO \\
\hline \multirow{3}{*}{ IIA } & \multirow{3}{*}{ T1 N1 M0 } & T2b NO MO & \multirow{3}{*}{ T2b NO MO } \\
\hline & & T1 N1 M0 & \\
\hline & & T2a N1 M0 & \\
\hline \multirow{3}{*}{ IIB } & \multirow{3}{*}{$\begin{array}{l}\text { T2 N1 M0 } \\
\text { T3 NO MO }\end{array}$} & \multirow{3}{*}{ T2b N1 M0 } & T1 N1 M0 \\
\hline & & & T2 N1 Mo \\
\hline & & & T3 NO MO \\
\hline
\end{tabular}

Table 4. Differences between T2 tumor size in $6^{\text {th }}, 7^{\text {th }}$ and $8^{\text {th }}$ edition of T2 classification

\begin{tabular}{|c|c|c|}
\hline \multicolumn{2}{|c|}{ T2 } \\
\hline \multirow{2}{*}{$6^{\text {th }}$ ed. } & $7^{\text {th }}$ ed. & $\mathbf{8}^{\text {th }}$ ed. \\
\hline \multirow{3}{*}{$>3 \mathrm{~cm}$} & $3-7 \mathrm{~cm}$ & $3-5 \mathrm{~cm}$ \\
\cline { 2 - 3 } & $2 \mathrm{a}: 3-5 \mathrm{~cm}$ & $2 \mathrm{a}: 3-4 \mathrm{~cm}$ \\
\cline { 2 - 3 } & $2 \mathrm{~b}: 5-7 \mathrm{~cm}$ & $2 \mathrm{~b}: 4-5 \mathrm{~cm}$ \\
\hline
\end{tabular}


Prevalence of N2 metastasis in patients clinically staged as T2 with NO by PET or PET-CT has been reported to range from $5.6 \%$ to $14.8 \%$ $[12,14-17]$. As we mentioned above, we believe that these values may be even lower because earlier editions of TNM were used to perform clinical staging. We have not found publications that evaluate exclusively N2 prevalence in such a selected population as our sample. After a thorough analysis of some publications cited previously [14-17], we came to revealing data. Gómez-Caro et al [14] describe a prevalence of N2 in cT2 (6th ed. TNM) of 13\%. Of 81 patients with cT2, 43 had tumours between 3 and $5 \mathrm{~cm}$ (clinical stage IB-IIA of 8 th ed. TNM), and of those 4 had occult N2 metastases, with a real prevalence of occult N2 of $9.3 \%$. However, in a later publication in 2012 , they report a $14.8 \%$ prevalence of $\mathrm{N} 2$ for the same tumour size [15]. Lee et al [16] describe a prevalence of N2 in cT2 (6th ed. TNM) of 8.7\%. Although is under 10\%, they described a prevalence of unsuspected N2 for tumours between 2 and $6 \mathrm{~cm}$ of 6.45\% (6/93). Finally, Gao et al [17] describe prevalence of $\mathrm{N} 2$ in cT2 of $11.8 \%$ including tumours up to $7 \mathrm{~cm}$ (7th ed. TNM).

PET-CT is recommended for non-invasive staging of the mediastinum (sensitivity: 80\%-90\%; specificity: 88\%-90\%; PPV: 49.3\%; NPV: $87 \%-98 \%)$ [1, 5-8]. There is controversy whether negative mediastinal result in PET-CT may spare invasive staging [10-12]. With a PPV close to $50 \%$, for patients with mediastinal uptake is mandatory an invasive approach, due to the high rate of false positive results (inflammatory - infectious disease). On the other hand, with such a NPV, we should ask ourselves if mediastinal invasive staging is necessary for patients without mediastinal uptake. For patients with clinical stage IB-IIA, the NPV of PET-CT described is under 90\%. Fernandez et al [12] described a NPV for PET-CT of 73.5\% for all lymph node metastases (N1 and N2), 79.1\% for N1 lymph nodes metastasis and $94.2 \%$ for N2 lymph node metastasis. In that publication, 81 of the 90 patients included belonged to clinical stage IB (T2 N0, 6th ed. TNM). From a metaanalysis carried out by Wang et al [18], only 130 patients with stage IB (T2N0) NSCLC from two studies were eligible for N2 analysis, yielding a summary NPV of $89 \%$ (95\% Cl: 0.84-0.95). These studies were those of Lee et al [16] and Gomez-Caro et al [14], with a NPV of 91\% and $85 \%$, respectively. Like Fernandez et al [12], both used the 6th edition TNM for clinical staging, including greater tumours than 8th TNM edition for clinical T2 tumours. Moreover, we have to consider the limitation of these results, since they may not be much accurate and could be even higher instead if we re-stage these patients with the 8th edition of TNM. It is well known that the greater the tumour, the higher the prevalence of occult N2 and, in consequence, the minor the NPV of the PET-CT [19].

Even though mediastinoscopy is the most accurate method to evaluate mediastinal lymph nodes with high sensitivity and specificity, in patients without nodal uptake in PET-CT it does not offer much benefit and the sensitivity drops to $25 \%-40 \%$ [11, 12, 17]. These diminished percentages partially explain the low prevalence of N2 patients when mediastinal PET-CT is negative. Although the number of patients that underwent mediastinoscopy in our study is too low to achieve significant conclusions, none of them had nodal metastasis in samples obtained neither by mediastinoscopy nor in surgical specimens. Similar results were achieved with the use of endobronchial ultrasound (EBUS) in patients without clinical mediastinal involvement [20]. Despite invasive mediastinal staging methods are of limited utility in this selected population, evidence suggest that unsuspected N2 disease is associated with equivalent 5-year survival compared to cN2 disease if adjuvant therapy is employed [21]. Those results support the use of adjuvant chemotherapy and radiation therapy when confronted with unsuspected N2 disease after surgical resection for stage IIIA-NSCLC [22, 23].

Although the results of the study are flattering and patients with clinical stage IB-IIA could undergo lung surgery avoiding preoperative mediastinal invasive staging, we know that our study has certain limitations: relatively low number of patients, inclusion of patients collected and analysed from a retrospective database (2010 to 2018: 26 (34.2\%)), mean number of nodal stations explored does not agree with international recommendations and a suboptimal mediastinal invasive staging in lower lobes and left tumours. In order to diminish the impact of this last factor, we have analysed the presence of mediastinal recurrences in the follow-up of those patients.

\section{Conclusion}

We should reconsider whether patients with clinical stage IB-IIA could undergo pulmonary resection without previous invasive mediastinal staging. International guidelines used earlier TNM's editions to recommend invasive mediastinal staging in these patients (including patients with tumours over $5 \mathrm{~cm}$ and/or N1 involvement) and it is demonstrated that sensitivity of invasive mediastinal staging methods in patients without clinical nodal involvement is very low. In our experience, we believe it might be an alternative since we did not have occult $\mathrm{N} 2$ metastasis and the NPV of PET-CT for N2 metastasis was 100\%. In order to propose a new recommendation to NSCLC guidelines, further research is needed to validate our results because of our study limitations. 


\section{Conflicts of interest and funding}

The authors declare that they have no conflicts of interest or funding.

\section{References}

1. Silvestri GA, Gonzalez AV, and Jantz MA, et al (2013) Methods for staging non-small cell lung cancer: Diagnosis and management of lung cancer, 3rd ed: American College of Chest Physicians evidence-based clinical practice guidelines Chest 143(5 Suppl) e211S-e250S https://doi.org/10.1378/chest.12-2355 PMID: 23649440

2. NCCN Clinical Practice Guidelines in Oncology (NCCN Guidelines) (2020) Non-small cell lung cancer Version Version 2.2020 - January 31, 2020 [NCCN.org]

3. De Leyn P, Dooms C, and Kuzdzal J, et al (2014) Revised ESTS guidelines for preoperative mediastinal lymph node staging for nonsmall-cell lung cancer Eur J Cardiothorac Surg 45(5) 787-798 https://doi.org/10.1093/ejcts/ezu028 PMID: 24578407

4. Detterbeck FC, Zelman Lewis S, and Diekemper R, et al (2013) Executive summary. Diagnosis and management of lung cancer, 3rd ed: American College of Chest Physicians. Evidence-based clinical practice guidelines Chest 143(5 Suppl) 7S-37S https://doi.org/10.1378/ chest.12-2377 PMID: 23649434

5. Vansteenkiste JF, Stroobants SG, and De Leyn PR, et al (1997) Mediastinal lymph node staging with FDG- PET scan in patients with operable non-small cell lung cancer: a prospective analysis of 50 cases. Leuven Lung Cancer Group Chest 112 1480-1486 https://doi. org/10.1378/chest.112.6.1480 PMID: 9404742

6. Gupta NC, Rogers JS, and Graeber GM, et al (2002) Clinical role of F-18 fluorodeoxyglucose positron emission tomography imaging in patients with lung cancer and suspected malignant pleural effusion Chest 122 1918-1924 https://doi.org/10.1378/chest.122.6.1918 PMID: 12475827

7. Verhagen AT, Bootsma GP, and Tjan-Heijnen VCG, et al (2004) FDG-PET in staging lung cancer. How does it change the algorithm? Lung Cancer 44(2) 175-181 https://doi.org/10.1016/j.lungcan.2003.11.007 PMID: 15084382

8. Reed CE, Harpole DH, and Posther KE, et al (2003) Results of the American College of Surgeons Oncology Group Z0050 trial: the utility of positron emission tomography in staging potentially operable non-small cell lung cancer J Thorac Cardiovasc Surg 126(6) 1943-1951 https://doi.org/10.1016/j.jtcvs.2003.07.030 PMID: 14688710

9. Detterbeck FC, Falen S, and Rivera MP, et al (2004) Seeking a home for a PET, part 2: defining the appropriate place for positron emission tomography imaging in the staging of patients with suspected lung cancer Chest 125 2300-2308 https://doi.org/10.1378/ chest.125.6.2300 PMID: 15189955

10. Kernstine $\mathrm{KH}$, McLaughlin KA, and Menda Y, et al (2002) Can FDG-PET reduce the need for mediastinoscopy in potentially resectable nonsmall cell lung cancer? Ann Thorac Surg 73(2) 394-402 https://doi.org/10.1016/S0003-4975(01)03432-4 PMID: 11845848

11. Cerfolio RJ, Bryant AS and Eloubeidi MA (2006) Routine mediastinoscopy and esophageal ultrasound fine-needle aspiration in patients with non-samll cell lung cáncer who are clinically N2 negative: a prospective study Chest 130 1791-1795 https://doi.org/10.1378/ chest.130.6.1791 PMID: 17166998

12. Fernandez F, Kozower BD, and Crabtree TD, et al (2015) Utility of mediastinoscopy in clinical stage I lung cancer at risk of occult mediastinal nodal metastases Thorac Cardiovasc Surg 149(1) 35-42 https://doi.org/10.1016/j.jtcvs.2014.08.075

13. Bankier AA, MacMahon H, and Goo JM, et al (2017) Recommendations for measuring pulmonary nodules at CT: a statement from the Fleischner society Radiology 285(2) 584-600 https://doi.org/10.1148/radiol.2017162894 PMID: 28650738 
14. Gómez-Caro A, Garcia S, and Reguart N, et al (2010) Incidence of occult mediastinal node involvement in cN0 non-small-cell lung cancer patients after negative uptake of positron emission tomography/computer tomography scan Eur J Cardiothorac Surg 37(5) 1168-1174 https://doi.org/10.1016/j.ejcts.2009.12.013 PMID: 20116273

15. Gómez-Caro A, Boada M, and Cabañas M, et al (2012) False-negative rate after positron emission tomography/computer tomography scan for mediastinal staging in cl stage non-small-cell lung cancer Eur J Cardiothorac Surg 42(1) 93-100 https://doi.org/10.1093/ejcts/ ezr272 PMID: 22290911

16. Lee PC, Port JL, and Korst RJ, et al (2007) Risk factors for occult mediastinal metastases in clinical stage I non-small cell lung cancer Ann Thorac Surg 84(1) 177-181 https://doi.org/10.1016/j.athoracsur.2007.03.081 PMID: 17588407

17. Gao SJ, Kim AW, and Puchalski JT, et al (2017) Inidications for invasive mediastinal staging in patients with early non-small cell lung cáncer staged with PET-CT Lung Cancer 109 36-41 https://doi.org/10.1016/j.lungcan.2017.04.018 PMID: 28577947

18. Wang J, Welch K, and Wang L, et al (2012) Negative predictive value of positron emission tomography and computed tomography for stage T1-2N0 non-small-cell lung cancer: a meta-analysis Clin Lung Cancer 13(2) 81-89 https://doi.org/10.1016/j.cllc.2011.08.002 PMCID: 3346713

19. Farjah F, Lou F, and Sima C, et al (2013) A prediction model for pathologic N2 disease in lung cancer patients with a negative mediastinum by positron emission tomography J Thorac Oncol 8(9) 1170-1180 https://doi.org/10.1097/JTO.0b013e3182992421 PMID: 23945387

20. Leong TL, Loveland PM, and Gorelik A, et al (2019) Preoperative staging by EBUS in cN0/N1 lung cancer: systematic review and metaanalysis J Bronchology Interv Pulmonol 26(3) 155-165 https://doi.org/10.1097/LBR.0000000000000545

21. Thomas DC, Arnold BN, and Rosen JE, et al (2018) The significance of upfront knowledge of N2 disease in non-small cell lung cancer World J Surg 42(1) 161-171 https://doi.org/10.1007/s00268-017-4165-6

22. Douillard JY, Rosell R, and De Lena M, et al (2008) Impact of postoperative radiation therapy on survival in patients with complete resection and stage I, II, or IIIA non-small-cell lung cancer treated with adjuvant chemotherapy: the adjuvant navelbine international trialist association (ANITA) randomized trial Int J Radiat Oncol Biol Phys 72 695-701 https://doi.org/10.1016/j.ijrobp.2008.01.044 PMID: 18439766

23. Douillard JY, Rosell R, and De Lena M, et al (2006) Adjuvant vinorelbine plus cisplatin versus observation in patients with completely resected stage IB-IIIA non-small-cell lung cancer [adjuvant navelbine international trialist association (ANITA)]: a randomised controlled trial Lancet Oncol 7 719-727 https://doi.org/10.1016/S1470-2045(06)70804-X PMID: 16945766 